Article

\title{
Navigating Ethnic Stigmatisation in the Educational Setting: Coping Strategies of Young Immigrants and Descendants of Immigrants in Norway
}

\author{
Katrine Fangen ${ }^{1, *}$ and Brit Lynnebakke ${ }^{2}$ \\ ${ }^{1}$ Department of Sociology and Human Geography, University of Oslo, P.O. Box 1096 Blindern, 0317 Oslo, Norway; \\ E-Mail: katrine.fangen@sosgeo.uio.no; Tel.: +47-91665112; Fax: +47-22855253 \\ ${ }^{2}$ Norwegian Institute for Urban and Regional Research, Gaustadalléen 21, 0349 Oslo, Norway; \\ E-Mail: brit.lynnebakke@nibr.no \\ * Corresponding author
}

Submitted: 14 June 2013 | In Revised Form: 27 June 2014 | Accepted: 3 July 2014 | Published: 18 August 2014

\begin{abstract}
Tolerance and equality are widespread norms in the official policy of many European countries. The educational system is an arena which even more than others is meant to foster equal opportunities by giving individuals the opportunity to strive for social mobility through their educational performance. Despite this, young people from ethnic minority backgrounds experience different forms of stigmatization in school and higher education, ranging from feeling marked as different to experiencing more explicit racism. This article analyses young people's coping strategies in order to combat or avoid such stigmatization. We will analyse the possible reasons why young people choose a particular strategy in a given situation, how successful that choice is, and changes in their choice of strategies over time. We will discuss how earlier experiences of support, encouragement and respect (or the lack thereof) inform the extent to which young people choose more approaching than avoiding strategies as a response to perceived ethnic stigmatisation in the educational setting. The empirical basis of the article is a sample of 50 biographical interviews with young people of ethnic minority backgrounds living in Norway.
\end{abstract}

\section{Keywords}

coping strategies; education; immigrants; navigation; Norway; social exclusion

Issue

This article is part of a regular issue of Social Inclusion, edited by Professor Ulf R. Hedetoft (University of Copenhagen, Denmark).

(C) 2014 by the authors; licensee Cogitatio (Lisbon, Portugal). This article is licensed under a Creative Commons Attribution 4.0 International License (CC BY).

\section{Introduction}

In contemporary Europe, young immigrants and descendants of immigrants are trying to establish a sense of belonging in the country they live in at a time when multiculturalism is disputed and right-wing populism is increasing (Kundnani, 2002; Verkuyten, 2004; Wiggen, 2012). The everyday surroundings of young people of ethnic minority backgrounds are fluctuating between an atmosphere of tolerance and equal rights on the one hand, and scepticism and ethnic labelling on the other. Norway is an interesting case in this regard, since its official policy highlights integration and tolerance. However, there has been announced a possible change of conditions for immigrants since the new Conservative Party and Progress Party coalition government took power in 2013 , with more restricted asylum policy as one possible consequence. On the other hand, there is not necessarily any consequences related to ethnic labelling. One could say that young immigrants 
and their descendants have, for many years already, experienced a situation where ethnic background is given importance in situations, either positively or negatively, for example through ethnic labelling. The Scandinavian countries are marked by a high degree of gender and income equality (Borchorst, 2011). Yet, as pointed out by Gullestad (2006), there is also a norm of equality, which can be perceived to be repressive. Everyone being equal means that those who are visibly different either have to assimilate in order to be part of the same equality, or feel that they do not fit in. Especially in the case of young immigrants and children of immigrants it is striking that many define themselves as foreigners after many years living in Norway or even having been born in the country (Øia \& Vestel, 2007).

School is an arena where ethnic stigmatisation can take many forms-from comments among peers to teachers' misrecognition of a pupil of ethnic minority background. More general experiences of stigmatisation at school or in higher education institutions are of course not something only young people with ethnic minority backgrounds experience. The whole educational system is based on hierarchies, between pupils who perform well and those who do not, and in the school yard and the university campus between those who are included in particular social circles and those who are not. This article has a more specific focus, however, by particularly focusing on those experiences of stigmatisation which might be related to ethnic prejudices. This is an issue which has not been tackled much in previous research (Wong, Ecless, \& Sameroff, 2003, p. 1203).

As shown in this article, young people use different strategies in order to combat or avoid such stigmatisation. This article will focus on young people's experiences of ethnic prejudice from teachers or fellow pupils in school and in higher education institutions. How do they react when experiencing stigmatisation in such settings? What factors lead to changes in their reactions over time? Our focus is on the three responses to perceived ethnic stigmatisation in an educational setting which we found to be the most common when analysing a sample of 50 interviews with young people from ethnic minority backgrounds living in Norway.

\section{Conceptual Frame}

Coping strategies are an individual's conscious and volitional efforts to regulate behaviour, emotions, thoughts etc. in response to stressful events and circumstances (Compas et al., 2001). These strategies do not operate in a vacuum; we can say that an individual is navigating between the established rules of conduct in an institutional setting and his or her need to maintain a sense of autonomy and respect through the use of strategies ranging from avoidance to resistance (Goffman, 1967, pp. 15, 49).
Coping strategies can be related to how to handle emotions related to different stressors, whereas in this article, we will focus on more problem-oriented coping-strategies, which are employed in order to maximise future possibilities. These strategies fit well with Albert Bandura's notion of 'coping-efficacy' (or selfefficacy, which is a synonym for the same phenomenon) (Bandura, 1982, p. 37). According to Bandura,

'The likelihood that people will act on the outcomes they expect prospective performances to produce, depends on their beliefs about whether or not they can produce those performances. A strong sense of coping efficacy reduces vulnerability to stress and depression in taxing situations and strengthens resiliency to adversity' (Bandura, 2001, p. 52).

Even though coping-efficacy is something different than self-consciousness, it is relevant when speaking about stigmatisation and exclusion in the educational sector, since what we have in mind here is the individual's belief that they can overcome the barriers to their future possibilities produced by prejudice.

A strong sense of coping efficacy makes it more likely that individuals will choose pro-active responses when experiencing ethnic stigmatisation, and in the absence of such stigmatisation, it is more likely that they will choose more passive responses. As expressed by Bandura,

'Unless people believe that they can produce desired effects and forestall undesired ones by their actions, they have little incentive to act' (Bandura, 2000, p. 9).

According to Bandura, there are four sources of copingefficacy: first, experiences of mastery; second, social models of people similar to oneself; third, social persuasion by others (for instance, support and encouragement regarding one's own ability to succeed) and; fourth, a person's mood and interpretation of physical stress reactions (Bandura, 1994).

In this article, we shall focus in particular on feelings of coping-efficacy related to having an ethnic minority background. What happens when one repeatedly experiences being stigmatised because of an ethnic minority background? Goffman (1967, p. 52) describes such a situation: 'In considering the individual's participation in social action, we must understand that in a sense he does not participate as a total person, but rather in terms of a special capacity or status...'. Ethnic minority background is not made relevant in all situations, and also by law it should not be treated as relevant-schools should strive to treat everyone as equals. However, based on the interviews carried out for the project, we can see that young people from ethnic minority backgrounds experience situations 
where they are treated negatively and-which should not be ignored-some where they are treated positively, because of their ethnic minority background. Thus, their background is made relevant in situations where, according to official policy, it shouldn't be.

In general, there are three parties to a situation of stigmatisation, corresponding to the humiliation triangle, to use Donald Klein's (1991) terminology. These are: the person who stigmatises, the person experiencing the stigmatisation and those who witness the stigmatisation and agree that this was an instance of stigmatisation. This means that ethnic stigmatisation is acted out in social relations, and the same holds for resistance towards stigmatory practices. Here, we are using the concept of stigmatisation in the broad meaning of the term, thus including everything from belittling, discrediting, etc. in close social encounters to more severe cases like racism (Fangen, 2006).

This article is structured as follows: following a presentation of statistics from the Norwegian context regarding young adult immigrants and children of immigrants in the educational sector, we will explain the methodology. Then we will give a general introduction to stigmatisation on the basis of ethnicity, as well as factors that serve as a buffer against stigmatisation. In the main section, we will analyse three central strategies that young immigrants and descendants of immigrants use when they experience stigmatisation in the educational setting.

\section{Ethnic Stigmatisation in Norway}

The majority of the interviewees (or their parents) came from Africa, Asia or the Middle East, with a minority coming from Eastern Europe. Most of the informants have a visible ethnic minority status through skin colour, facial characteristics, and sometimes clothes and religious symbols (e.g. hijab). Whereas racism based on appearance is widely seen as unacceptable in today's Norway, a dark skin colour, or religious symbols like hijab, denote cultural difference and it is on this basis that more subtle forms of exclusion develop (Gullestad, 2006). Previous research indicates that there is no automatic link between belonging to a stigmatised ethnic minority and experiencing emotional distress (Miller \& Major, 2000). Social vulnerability is connected to one's general life situation at a given point in time. Higher education, a stable and well-paid job, and a family of one's own, as well as a nice home and a good social network, are all factors that might serve as a buffer against experiences of humiliation and exclusion (Lindner, 2000). Furthermore, having a robust network consisting of both those from the ethnic majority and those with the same ethnic background as oneself can be a buffer against the negative impact of humiliating experiences (Fangen, 2006).

In the wider perspective, the extent to which immi- grants and descendants experience barriers is associated with factors such as knowledge of the dominant language, ease with widespread cultural codes of the ethnic majority population, and their level of skill in relating to different institutions in the country of residence (Portes \& Rumbaut, 2001, p. 46). Those interviewed as part of our project differed in migration categories (from labour migrants, refugees, to the descendants of immigrants), the length of residence in Norway, and in socioeconomic status. They ranged from those typically seen as multiply marginalised to 'success immigrants' in higher education and in highly skilled jobs. Most of the descendants had experienced exclusionary experiences due to the fact that they or their parents were immigrants. However, for those who have achieved a high position in the labour market, this had often taken place earlier in their careers, while they were working in the service sector (Fangen \& Paasche, 2013) or during their school years; it is these experiences on which we will focus here.

Compared with other European countries, immigrants and their descendants in Norway have a relatively high participation rate in the educational sector (Fangen, Fossan, \& Mohn, 2010). In 2010, 97 percent of descendants and 77 percent of immigrants made a direct transition from lower to upper secondary education. The average for all students is 96 per cent (SOPEMI, 2010). Many of those immigrants who do not enter upper secondary school do not do so because they are only resident in Norway for a short period of time. As for descendants of immigrants aged 19-24, their participation rate in higher education is somewhat higher than that of the ethnic majority population (Støren, 2010). Overall, the completion rates of immigrant and descendant youth are lower than those of the majority population, but research on subgroups indicates that the difference in completion rates can be traced back to the background (income and education) of the parents (Fekjær, 2007).

\section{Methodology}

There have been a number of previous studies of coping strategies related to stigma. Most of these studies are quantitative, using for example the "Ways of Coping Questionnaire" or the "Multidimensional Coping Inventory" (Puhl \& Brownell, 2003, p. 72). Such studies have the advantage of being able to say something about the frequency of the use of certain coping strategies in certain categories of the population. Since we conducted a qualitative study, with a sample of 250 interviews in seven countries and 50 interviews in the national sample we will use here, we cannot generalise by drawing conclusions about the frequency of using certain coping strategies among young people from ethnic minority backgrounds in general. Also, the purpose of our study is different; it does not aim to say 
which strategy is the most frequent, but rather to say what motivates different strategies and show changes in the strategies used over the course of an individual's life. We will discuss the merits and pitfalls of different strategies in given situations, and this is not easily done with a statistical study which gives results on an aggregated level.

The empirical basis of this article is a series of biographical interviews with young adult immigrants and children of immigrants conducted in Oslo for the research project EUMARGINS-On the Margins of the European Community. The EUMARGINS project explores the inclusion and exclusion of young adults between 18 and 25 in seven European countries. In this article, we analyse interviews from the Norwegian data sample. All interviews focused on experiences of inclusion and exclusion in different arenas, such as schools, neighbourhoods, work places, etc. The interviewees were told that the interviews were being collected for a European project that focused on exclusion and inclusion of young immigrants and descendants in Europe. They were informed that they could visit the web page of the project if they were interested in more information about it, and were also invited to ask if they wanted the project described in more detail. The importance of collecting the experiences of young immigrants and descendants in order to come up with advice as to how to make conditions more inclusive was stressed. The interviewees were also informed that their names, as well as any other recognisable criteria, would be changed in order to ensure anonymity.

The interviews were structured as biographical interviews, where the interviewees were asked quite open questions about their life in Norway from arrival (if they weren't born there) to the present day. They were prompted in particular about experiences of inclusion and exclusion. The interviewers tried to grasp the interviewees' own concepts and understandings of inclusion and exclusion, and they used mostly more everyday concepts, rather than more abstract ones (like inclusion/exclusion). All interviews for the project were structured around questions of experiences of inclusion and exclusion in various arenas, such as education, work, neighbourhood, family and peers. They took the form of semi-structured biographical interviews, where discussion of changes over time were particularly prompted. For the purpose of this article, we searched through the entire Norwegian data sample for narratives about school and education. Based on this search, we copied relevant interview excerpts, including the background information necessary in order to interpret each of them in a separate word document (Fangen, 2012). We combined the analysis of the interviews with intermittent reading of the interviews in their entirety, one at a time. Often, such an alternation between an overview and depth of insight gave the best analysis of the material. Also, when we were transcribing interviews, or just after the reading of an interview, we wrote memos about what was important in the interview and how to interpret it. In this way, we gradually got an overall picture of the material (Fangen, 2012). The quotes were edited true to content, but with the deletion of repetitions and reformulations to increase their clarity in written form.

As the length of the present article does not allow us to present each interviewee from the sample, we chose a selection of interviewees to use as examples for the purposes of this paper. Experiences of ethnic stigmatisation in school and/or higher education institutions (for those interviewees who have attended those) were present in all interviews. Our sub-sample was made strategically in order to reveal different methods of coping with stigmatisation in school. Since we wanted to include examples of stigmatisation in higher education institutions in addition to examples of exclusion in primary and secondary school, the sub-sample of ten informants is somewhat biased towards those who have succeeded in pursuing higher education. But in our national sample of 50 interviews, this bias was not so strong, since the purpose when recruiting interviewees was to gather 'a variety of experiences' (Fangen, 2012).

The interviews were conducted partly by the authors of this article (of whom one was the project leader and another was a research assistant), and partly by other research assistants or master's students (Finne, 2010; Kvittingen, 2011), and the interview sites included offices, cafés and in a few cases, the interviewees' homes.

As in all qualitative studies, it is hard to generalise with the findings because the sample is limited. However, we will argue that our findings are consistent with much earlier research, also of a quantitative nature, as is evident in the references we give.

\section{Coping Strategies}

Our main interest in this article lies in the interaction between young adults with ethnic minority backgrounds who have experienced exclusion in the educational setting and the people who stigmatise them. However, our focus is on the experiences of the young people themselves. We are not evaluating whether or not they really were stigmatised, but the way they perceived being stigmatised and the way they responded to it.

\subsection{Avoiding}

In the literature on coping strategies, a distinction is often made between approaching strategies and avoidance strategies (Goffman, 1967). This is similar to Miller and Major's (2000) distinction between primary control strategies and secondary control strategies. Approaching and primary control strategies aim at changing the stressful situation (by, for example, confronting it), whereas avoidance and secondary control 
strategies aim at adapting to the stressful event (by, for example, withdrawing) (Miller \& Major, 2000). From our interviewees, we heard many examples of avoidance strategies. For some, these were former habits, whereas following a changing environment, higher education or an increase in support, they had changed to more approaching strategies. We will illustrate such changes by using the same subjects as examples for several of the strategies described in the following sections.

Avoidance is the most defensive strategy young people use when experiencing exclusion. This strategy is closer related to emotional arousal and distress. Instead of trying to change the situation or the environment, this strategy implies that the young people avoid situations and settings where they can be negatively stereotyped. According to Miller and Major (2000), the most common avoidance strategy is not complete avoidance, but selective avoidance of some arenas of life, such as choosing who to socialise with. In our material, we found many examples of such selective avoidance. Often, there was a discrepancy between who the young people wanted to interact with, and who they ended up interacting with in order to avoid further exclusion.

Take the case of Isir, who is a 19 year old upper secondary school pupil and the only one in her class who is not ethnic Norwegian. She immigrated to Norway from Somalia as an asylum seeker when she was 11 years old. She sees a strong contrast between the way her classmates treat her and how they treat other classmates. After numerous experiences of being stereotyped, she stopped approaching ethnic Norwegian peers. It upsets her when her classmates approach ethnic Norwegians with casual conversations about spare time activities, whereas when they speak to her they seem preoccupied with her ethnic background and religion:

Sometimes I just feel that they [ethnic Norwegians] regard us as if there is something wrong with us. (...) I speak Norwegian. We are doing the same assignments (...). The only difference is skin colour and the way one dresses. I have a head scarf and you don't. What's that got to do with it? (...) I feel as if they think that we are not the same, that we are not worth as much as them, that they regard us as if we still are asylum seekers, see? (...) I feel like they perceive me as the same girl as [I was] when I came to Norway.

Isir finds it mundane and upsetting being repeatedly asked the same questions about her background.

When we talk, a conversation goes like 'Ok, where do you come from? How long have you been here?'(..) The conversation becomes very boring. I think, 'oh my God, is this an interview? I'm not in a reception centre for asylum seekers now. I've done that before, let's talk about something else.' Let's talk about boys or shopping, going to cafés! Because that's what you do when you're with that Norwegian girl over there, right? You talk about fun stuff, but with me you only talk about 'well, what do you believe in?' It's boring stuff like that.

The conversations Isir has with her class mates tend to be rare and brief, and because Isir finds the topics dull, she makes no attempt to lengthen the conversation herself either. 'When it's like that, you just shut up'. Staying aloof in conversations could be seen as a first stage of avoidance. Isir wishes her classmates would invite her to come along with them:

They think that 'she doesn't go to parties'. Kind of, like, prejudices, see? 'Do your parents allow you to go?', they ask. [I think:] Yes, yes, yes, don't ask! You don't ask your Norwegian friend 'do your parents allow you to go?' You just say 'Come on, let's go. Shall we go shopping tomorrow? Shall we go to a café on Saturday?'

Isir has tried asking others if they want to meet in their spare time, but so far no one has agreed. As a consequence of her strained encounters with ethnic Norwegians, Isir has started searching out peers with an ethnic minority background. With them, she can relax:

I get upset by [experiencing] that [prejudice], right (...) Therefore, I am more interested in hanging out with Parveen or someone else, from the same or another foreign background.

We can see that the reason Isir ends up with withdrawing herself from one social circle and building an alternative network, is that her previous attempts at approaching others did not succeed. It is her negative experiences that have led her to change who she relates to.

Both social psychological researchers (Major \& O'Brien, 2005) and social scientific researchers (Portes \& Rumbaut, 2001) have pointed out that experiencing stigmatisation can lead to increased identification and interaction with others who have a similar stigmatised background. Being with other people from similar backgrounds is linked to less depression and more to positive self-esteem (Schmitt \& Branscombe, 2002). Contact with other people from a similar background gives not only a 'sanctuary' from prejudice, but also leads to social, informational and instrumental support. Furthermore, one can experience mutual understanding, a sense of belonging and acceptance through such contact (Miller \& Major, 2000; Major \& O'Brien, 2005). Isir receives a sanctuary from prejudice by associating with others with an ethnic minority background. However, the most painful part of her experience seems to be that she does not accept being categorised as dif- 
ferent from ethnic Norwegians, but ethnic Norwegians presume that a difference exists between them. This reveals the emotional distress related to avoidance, and illustrates that to withdraw from contact in order to avoid being stereotyped is not necessarily a strategy which leads to greater personal harmony.

For Azadi, however, increased interaction with others from the same background in order to avoid contexts where he was stigmatised by ethnic Norwegians, was a strategy that lead to an increased feeling of wellbeing. Azadi is 26 years old and has finished his master's degree at a Norwegian University. He immigrated to Norway from Iran via Iraq as a teenager. After several exclusionary experiences related to his background, Azadi has strengthened his Kurdish network.

Azadi: Because (...) I was not allowed to talk my mother tongue at school...This means that you aren't very included. Then you feel that something is wrong. And this has actually made me more engaged in my background. (...) Politically, in Kurdish circles, and ethnically we have been suppressed in many countries. It makes me more conscious of my background. In Iraq I didn't give a s... about being a Kurd. But in Norway something forces you to carry it with you further, to strengthen it.

Isir and Azadi's withdrawal strategies differ in the sense that for Azadi it has been accompanied with a cognitive shift in who he identifies with, whereas for Isir it has not. But there can be a cost related to withdrawing like this, and emphasising one's ethnic identity as the main source of self-efficacy. Major and O'Brien (2005) state that people who perceive their stigmatised social identity as a central part of their self-identity are more likely to see themselves as targets of personal and group discrimination, especially when prejudice cues are attributionally ambiguous.

There are examples of young people from ethnic minority backgrounds who relate to successful others from the same ethnic background, ethnic identity can be a source of pride (Fangen, 2007a, 2007b). Within a selfefficacy framework, experiences of negative social interaction with ethnic Norwegians can be seen as a failure experience, however. Failure experiences can undermine self-efficacy. Disengagement from settings where one expects to experience failure can be seen as a way of moving one's energy elsewhere, to areas of life where one expects to be in greater control and at greater ease. Bandura (1994) notes that failure experiences can particularly negatively impact self-efficacy when failures occur before a sense of efficacy is firmly established.

\subsection{Working Harder}

One can assume that repeatedly experiencing exclusion may at some point lead to expecting exclusion and hence that the individual will tend to interpret ambiguous possible stigmatising situations to have a negative meaning. Conversely, someone with a high degree of self-efficacy may have a "robustness" which can open them up to different solutions than withdrawal when experiencing stigmatisation. A strategy that was seen in the narratives of several of our informants was a strategy equivalent to what Major and O'Brien (2005) describe as 'working harder'. Findings from quantitative studies show that many young people from ethnic minority backgrounds have an extra drive to perform well (Lauglo, 1999). Working harder can be based on past negative experiences, but also on encouragement and advice from others and general knowledge about how to achieve a high level of success in a particular society. According to Lauglo (1999, p. 79), the situation of being an immigrant can in itself contribute to an ethos of 'working harder'. He lists several possible reasons for this. One aspect of this is immigrants seeing themselves as

outsiders who are not really entitled to be treated on equal terms with other citizens (...) The parents might stress that 'it is tough out there' and that their children therefore must learn to work harder than others in order to stand a chance. (1999, p. 79)

This was quite salitent in the examples we will cite in this section.

Jasmina is a 25-year-old master graduate who fled the war in Bosnia as a child. When she first came to Norway, she lived in a small town in the west of the country. She did well at school, but socially speaking she experienced some rough times, especially at primary school, but to some extent also during upper secondary school. She told us: 'I wouldn't say [I was] bullied, but rather I was excluded by the other girls in class. Because I wasn't cool enough, because I didn't have cool clothes while we lived in a reception centre for refugees.' Her response to this situation was 'I had to do everything to fit in, so that I wouldn't seem even more different from the others'. Jasmina believes the main reason she was excluded was that she was foreign and did well in school, and that presumably during her teenage years 'wanting to be cool and popular while you're not' may have been at the core. When Jasmina had experienced stigmatising comments during her school years, she had used strategies of trying harder in order to be liked and accepted, and had tried to adhere to the social norms of the surroundings.

Jasmina had experienced stigmatisation from a teacher during upper secondary school. The teacher was pleasant to all the girls in her class, except her. She told us that the teacher had paid the other girls compliments, and despite the fact that Jasmina always did her homework, the teacher gave her negative feedback. Jasmina was convinced the teacher had treated 
her that way because she wasn't ethnic Norwegian. 'I did everything better, faster and [her attitude was] "No, this isn't good enough", whereas others got a pat on their shoulder for trying,' Jasmina states. The other girls in Jasmina's class had also noticed how the teacher 'tried to push [her] down a bit.' During that period, Jasmina often came home from school in tears. She had thought: 'It will probably pass, maybe it's like this in the beginning, I just have to work harder, maybe it's me.'

Working harder can be associated with a view that one requires something extra, since the starting point is not equal for people with an ethnic majority and ethnic minority background. For instance, there may be a view that more education or skills are needed in order to have the same opportunities as people with an ethnic majority background. The information one gains can be central to one's expectations about future exclusion, and hence one's long-term strategy to avoid exclusion. Azadi, mentioned in the previous section, is willing to increase his qualifications further in order to get employed in the sector he desires to work in. When the interviewer asked whether this had been necessary in order to get the executive officer position he was aiming at, he responded: "Yes, for an immigrant; unfortunately." Thus, we see that his strategy is not merely withdrawal (as in the previous section), but also working harder, by increasing his qualifications further. This is often the case; young people use a combination of different strategies in order to overcome stigmatisation and social exclusion. It is the total set of strategies that define their specific way of dealing with their stigmatised social status. For Azadi, the strategy of increasing his qualifications seemed to have worked, as he had eventually got a position that reflected his qualifications.

The experiences of others of our interviewees who have worked hard to increase their educational competences point in the same direction. 24-year-old Sahel, a descendant of Indian immigrants to Norway, had considered becoming an engineer, but chose medicine instead. An important factor influencing his decision had been his ethnic minority background.

Interviewer: So you were thinking a bit about job opportunities as well? That when you were finished [with secondary upper school] you thought that as a doctor, there is high demand for doctors?

Sahel: Yes, exactly. I thought about that as well and it is also related to being foreign and being a job applicant, like, that I think it's easier to get a job in the health sector because there are quite a lot of foreigners working there. Ehh...as opposed to job seeking in the business sector. I think it's worse being a foreign job applicant there.

When Sahel was asked whether education might be a means to gain respect and recognition, he responded "yes, absolutely", and told us about an incident when he was training for at a petrol station. Sahel said that the girl who trained him for the job initially was 'very, you can say, racist.' Before he started the job, she had made it clear that if he started, she would quit. However, the girl's offhand attitude towards Sahel had stopped when she had heard that he studied medicine.

A motivating force for working extra hard and aiming high can be a desire to stand out less in a stigmatised sense by trying to excel in a field and drawing attention to one's strengths. Gagan, a descendant of Indian immigrants and a PhD candidate in medicine, stated that pursuing higher education can be a strategy to counter exclusion and feel safer:

Gagan: People who are children of first generation immigrants will always have a kind of insecurity inside, exactly because they are different, they are foreigners, and therefore they desire-just like everyone else, that their surroundings accept them, and think that they are good. To become a doctor is an easy way of gaining recognition. (...) When you are a second generation [immigrant], you are rootless and insecure and want recognition from your surroundings. And to become a doctor is one of the best ways to achieve it.

Similarly, 26-year-old Bashir, a pharmacy student and descendant of Indian immigrants, said that education can be a way of improving esteem from others and increasing a sense of belonging:

Interviewer: What do you think influences you when it comes to [getting] a good education and a good job? (...)

Bashir: It definitely helps your self-esteem. You grow up here and feels that you are not very much at home here. But you were born here, so it affects your self-esteem a lot and then it is very importantI feel that it has helped my self-confidence to have a good education.

In these cases, we can see that the young immigrants and descendants go into higher prestige education in order to increase their recognition in Norwegian society. Their strategy is an attempt to get a status position in a society where they feel like outsiders.

The strategy of working harder can be viewed as an attempt of conforming to the values of the country of residence. We saw how Jasmina had tried to combat a sense of exclusion by attempting to conform to what she thought were her teacher's expectations and her peers' social expectations. Similarly, several informants aimed at elite professions in order to gain recognition.

\subsection{Confronting}

'When they are empowered with sufficient social re- 
sources, members of ethnic/racial groups are more likely to confront racial bias and discrimination, regardless of their cultural backgrounds', argue Noh and Kaspar (2003), based on a quantitative study of South-East Asian refugees in Canada. Also our sample shows that to deal with exclusionary experiences head-on requires an already established sense of coping-efficacy. An example is Bushra, the 24-year-old daughter of economic migrants from Pakistan who has a master's degree in natural sciences. Her strategy of confrontation had been consistent throughout the exclusionary experiences she shared from her childhood, youth, as a student and as an adult. Throughout primary and upper secondary school Bushra was, against her will, placed in a class for Norwegian as a second language, even though she spoke the language fluently. She said that she had been unfairly treated, and that she was placed in the wrong class merely due to her ethnic minority background. Bushra commented that in kindergarten she had in fact been the one correcting her peers' way of speaking Norwegian. She said that while languages were not her favourite subjects in school, the problem had been that she wasn't treated as an individual.

For much of her school years, Bushra's strategy to deal with her Norwegian class placement had been one of direct and repeated confrontation. She had approached her teachers numerous times requesting to be accepted into regular Norwegian classes. When the school staff had said that her parents had immigrated, she had replied: 'But I didn't immigrate. I was born here. I am Norwegian.' On some occasions, she had also walked out of the class room. Hence, her strategy had been one of protest, often taking place as confrontation and boycotting. In the end, her claims had reached the headmaster. The result of Bushra's claims was that she had been accepted into a regular Norwegian class, where she had worked her way up to passing her final Norwegian oral exam in upper secondary school with the top grade. For Bushra, getting accepted into the class for Norwegian as a first language could also be seen as a kind of encouragement that had triggered a heightened sense of self-efficacy.

At a later stage in life, Bushra had again used a confrontation strategy, when as a student she felt pigeonholed by a professor:

We were [in the mountains on an excursion]. He said to me: 'You don't know much about this, do you? Because you immigrants don't spend as much time in the forest as we Norwegians do.' And I looked around and said: 'You know what? All the Norwegians I know, those who are born and raised in the city, not many of them spend time in the forest.' I stood there feeling that he meant that I'd be less skilled than the others because of my background. (...) I got like: 'No, I am Norwegian actually and I'm as Norwegian as anyone else. I was born and raised in the city, so it's not natural for me to be in the forest and climb in trees and do that kind of stuff.

Spending time in nature is often seen as a central symbol of Norwegian national identity (Witoszek, 2011), and the professor had stereotypical expectations of Bushra because she was the daughter of immigrants. After having gone through various identity stages during youth-defining herself as Pakistani at one stage and Pakistani-Norwegian at a later stage, the experience with the university professor had elicited a Norwegian period. Later in the semester, when Bushra had been the only one in her class to obtain an $A$ grade in the exam, she had approached the professor, once more underlining her 'Norwegianess':

I said to him: 'Do you know who got that A?' He looks at me. [I said] 'It was me! Because I'm Norwegian' I don't think he meant to be personal. But I took it [the event in the excursion] very personally.

Confronting prejudices can come with a cost. Miller and Major (2000) point out that: 'successful adaptation of stigmatized persons is typically not achieved without a price'. They point out that trying to influence the prejudice of others 'demand[s] commitments of time, money, energy and other resources', and thus it is not a strategy available to everyone. Some young people from ethnic minority backgrounds who use direct confrontation as a strategy seem particularly 'resourceprivileged.' Confronting school staff repeatedly during many years the way Bushra did, demands persistence and confidence that perhaps not everyone has, and the cost of such actions may differ for different individuals. Compared to many of the other interviewees, Bushra comes off as an exceptionally confident individual who tends to take an assertive approach to challenges. One example of this was her job-seeking strategy before graduating, where she had been unusually forward when approaching the prospective employer she wanted to work for. She had reached her employment goals with the job she wanted. Bushra believes that one's own individual job-seeking strategy, as opposed to ethnic background, is the decisive factor in obtaining employment. Some of her friends from an ethnic minority background had aimed low when applying for jobs following graduation, whereas she had been determined to only apply to jobs she was qualified for. For Bushra, the support of her father had had an impact on her degree of self-efficacy in relating to ethnic Norwegians. Bushra said that her father had always given her strong support, encouraging her and standing up for her.

Jasmina had also used confrontational strategies when she had experienced prejudice, albeit with a less consistent strategy than was the case for Bushra. Jasmina explained that it was 'only' in the beginning that 
she had experienced exclusion and that she had had a lot of friends in secondary school. Things had changed when she learned Norwegian: 'When I knew more Norwegian, I could defend myself. If anyone blamed me, I could stand up for myself,' she said. Jasmina also felt a turning point had been when her mother had had a serious talk with her, telling her that she had to stand up for herself and that the way the other kids were treating her was wrong.

Generally speaking, Jasmina had felt more confident in upper secondary school, a time during which she said she generally 'toughened up' after she started to play handball. It had also helped to start a new class with 'new people who brought positive traits to the class room.' Hence, there were both changes in Jasmina's environment and personal changes within herself. Jasmina had started positioning herself differently when she experienced exclusion. Whereas in the beginning she had done everything she could to be liked, she said that after a while she had started to be able to read people better and determine who was genuine. Her attention changed from focusing on who liked her, to who she liked and sensed she could trust.

The story of Ping, a 27-year-old master graduate and the daughter of Chinese immigrants, also illustrates how self-perceptions can have an impact on strategies in facing exclusion. Ping had been teased as a child, but had felt increasingly included as she had become older. Ping's process towards experiencing less exclusion was linked to experiencing a more and more ethnically diverse environment-first when moving to a school with more diversity for upper secondary school and later when she moved to Oslo. Ping had already noticed the impact of a diverse setting when she started at upper secondary school. 'People had seen a bit more;' she explained, and added that in Oslo 'it was even better, because it is even more mixed.' Ping stated that today the older you are the more confident you feel about yourself. When Ping was younger, her need for being affirmed by others had been greater. When she was younger, she had wondered whether there was something wrong with her because she didn't have friends. Ping said that those who act in discriminatory ways today are the ones 'who have a problem,' not being able to deal with the way she looks. She explained that today,

If people act badly, ok, I answer back and don't care about them. I don't walk around thinking 'oh, he treated me so badly'. I just think: ok, such people aren't worth bothering about.

Another side of her being less socially vulnerable than before, is that she does not feel humiliated by such experiences, but instead says ' [I] don't care about them.' Ping's case illustrates close links between experiencing inclusion, self-confidence and a strategy of answering back when she experiences ethnic labelling. Positive experiences of inclusion has led to her quickly bouncing back when she experiences exclusion.

For some, a change of environment might be the setting that triggers more positive experiences, since the people from the past who discredited them are no longer there. Both Ping and Jasmina had changed environments and thus had experienced increased 'mastery' of being different as time passed. Someone who generally feels included in different areas of their life may choose to confront those who act exclusionarily or shrug it off as an insignificant event that they deem unrepresentative of their life or of Norwegian society (Fangen, 2006).

\section{Discussion}

In this section, we will analyse possible reasons why the young people interviewed use a particular strategy in a given situation, how successful that choice has been and changes in their choice of strategies over time. We will also discuss the structural barriers and other barriers that limit the possibilities of proactive responses that young people from ethnic minority backgrounds have in situations where they are met with ethnicity-based prejudices or racism. Moreover, we will discuss how earlier experiences of support, encouragement and respect (or the lack thereof) inform the extent to which the young people chose more approaching, rather than avoiding strategies

Bandura (1994) states that that the most effective way to develop self-efficacy is 'through mastery experiences. Successes build a robust belief in one's personal efficacy' whereas 'failures undermine it, especially if failures occur before a sense of efficacy is firmly established. (...) A resilient sense of efficacy requires experience in overcoming obstacles through perseverant effort.' Mastery experiences can take the form of having confronted the prejudiced person, and having experienced a successful result after doing so. This is the first source of self-efficacy, according to Bandura. In the case of Bushra, we see that she chose to confront her teachers and later on the headmaster because she had not been allowed to join the class for Norwegian as first language. By doing so, she not only stood up for herself, but aimed at influencing her environment. This can be seen as an example of 'overcoming obstacles through perseverant effort' (Bandura, 1994). Her current strong sense of control in tackling situations could partly stem from these mastery experiences, where she repeatedly confronted the teachers over time, and in the end succeeded in achieving the result she aimed at. In her case, we see that she faced some barriers, but that she chose not to give up because of them. Why did she have the courage to do so? We can see two possible reasons for this. One of them resembles the third source of self-efficacy, according to Bandura, namely social persuasion by others, for in- 
stance support and encouragement regarding one's own ability to succeed. This condition was present in Bushra's case, since she received continuously support from her father, who taught her to stand up for herself. Her father probably was also a role model for her, this being the second source of self-efficacy (see description of these in the introduction). Furthermore, we cannot rule out possible inborn personality traits, which might contribute to Bushra's mood and her personal interpretation of stress situations. This corresponds to the fourth source of self-efficacy according to Bandura's theory. Bushra's general approach to life appears to be facing challenges head-on and not expecting less than she feels she deserves. It seems plausible that with her general style of dealing with challenges, such as approaching authorities like her school headmaster when she felt unfairly treated, could have come more naturally for her, and hence with a lower cost than for many others.

Personality can be a trait which is genetically predetermined. However, structural and social/environmental factors also have an influence on which strategy one chooses in a given situation. In particular, a change of environment can imply that an individual enters a social environment where people are more inclusive (social support) or where there are more people similar to him- or herself (referring to the second and third source of self-efficacy according to Bandura). This was the case with Ping, who had moved to an area where more immigrants lived, and where she no longer felt as different as she had previously felt from other pupils. This boosted her self-esteem. A change of environment can also possibly lead to more experiences of mastery, which again can impact the person's mood and interpretation of situations. This illustrates that all the four sources of self-efficacy as defined by Bandura (1994) seem somehow related to each other, rather than operating in a vacuum.

In this article, we have discussed three strategies young immigrants and descendants use when experiencing exclusion: avoiding, working harder, and confronting. These are three of many possible coping strategies in stressful situations, or, in this case, a response to ethnic stigmatisation (in the methodological section we mentioned some of the many coping strategies found in previous research on this topic). In our sample, other coping strategies, such as emotionally focused strategies, talking with others, turning to religion, etc., were not as often mentioned. However, the interviewer did not explicitly ask for other strategies either, since the overall theme of the interviews was experiences of inclusion and exclusion in different areas of the participants' lives. In particular, the interviews focused heavily on arenas such as school and labour market, and these are arenas where mastery experiences are of great importance. This might explain the fact that the interviews revealed mainly problem oriented strate- gies, rather than emotional or psychological ones. Nevertheless, withdrawal or avoiding specific networks of people, might be seen as less problem oriented; it is more about avoiding situations where problems (i.e. ethnic labelling) occur. The consequence of avoidance can be sanctuary from prejudices, but at the same time emotional distress, and consequently a lack of available social capital related to contact with people from the ethnic majority population. Thus, this strategy has psychological and potentially socio-economic consequences. When Isir wanted to be an equal participant in her peer group with pupils who had ethnic Norwegian background but was unsuccessful, she became distressed. However, it was a relief for her to make other friends who also had an immigrant background, even though this was not what she originally aimed for. By contrast, Azadi did not have the same desire to feel included with ethnic Norwegians, and was happy after he joined a social circle with other Kurds. Earlier research has shown that to withdraw from social networks with people of the majority ethnic group can give a sanctuary from prejudice, but as a consequence one might feel less included in the country of residence (Fangen, 2006a, 2006b). In addition, minority networks do not give the same access to jobs and future possibilities in general (Fangen, 2010). Another strategy of withdrawal that we haven't discussed in this article is the strategy of leaving school entirely. In some cases, in particular among young ethnic minority men, this can be related to a 'street wise' and even a partly criminal career (Fangen \& Frønes, 2013). (Self-)evidently, this is not beneficial for maximising a person's chances in the education system or the labour market, but it can give them access to certain kinds of low skill jobs.

By contrast, the strategy of working harder can be more successful. We can see that in the cases of Sahel and Gagan; aiming for high status professions provided them with the respect of others, which they formerly lacked of in some situations. According to Lauglo, the strategy of working harder could be partly motivated by the fact that youth from immigrant backgrounds think that they need more competence than others in order to compete on the labour market on a level footing, but it can also be motivated by the fact that due to language difficulties and other obstacles, they simply have to work harder in order to achieve the same results as their friends who do not have an immigrant background. In either case, this is, according to Lauglo, simply a 'basic human trait. They respond to perceived necessity' (Lauglo, 1999, p. 97). Finally, the consequence of confrontation can be that prejudices are fought and that environments are changed for the better, although in some cases, confrontation might also lead to conflict or to further exclusion because the individual will be marked as 'difficult'. However, in Bushra's case, we can see that her confrontational strategy was more related to showing what she was good at, ra- 
ther than entering into conflict. Our informants use confrontation in situations where they sense that they risk a loss of respect (cf. Folkman et al., 1986).

\section{Conclusion}

Quantitative research on different coping strategies shows that so-called emotion-focused strategies, related to dealing with the negative emotions that stressful encounters trigger, are less effective than problemoriented strategies that deal more directly with what has happened (Noh \& Kaspar, 2003). This is similar to Millar and Major's distinction between primary and secondary coping strategies, as discussed earlier. Problem-oriented strategies resemble primary control strategies in that they aim at changing the situation. Emotion-oriented strategies resemble secondary strategies in that they aim at adapting to the stressful situation. The latter is more passive than the former. Withdrawal can be a wise strategy when the environment is marked by strong ethnic prejudice, but when it is not, confrontation - in a positive sense that is highlighting one's own competences - is possibly more beneficial.

When having experienced prejudice many times in the past a person can start expecting prejudice in situations where they do not occur. In other words, there will be an increase in 'false alarms' (Barrett \& Swim, 1998). The positive thing about a generalised 'cultural mistrust' is that the individual can detect prejudice and immediately react to it, for example by saying that he/she will not accept being treated badly. However, the cost is that he/she will live in a state of heightened alarm, which in itself is stressful. We believe that there are factors which can tell us which individuals will choose confrontation when faced with ethic stigmatisation and which will react with withdrawal. To be able to confront others successfully requires social support of people who can encourage the person to stand up for him or herself and to negotiate his/her individual qualities in order not to be discriminated against. It also requires some degree of resilience, which means not being deterred by structural and social barriers, but rather choosing to fight back and stand up for oneself in the face of stressful situations. As noted by Bandura, this can be related to previous mastery experiences, but also, we would argue, personality and genetic factors play a role here; this is supported in research on so-called 'resilience' (see Fangen \& Frønes, 2013).

To have a broad repertoire of strategies, and being able to alter between them seem to be the most beneficial competences. Such competences develop more easily if the person has both experience of being met with prejudices in the past and experiences of social support. Also, his or her own mastery experiences play a positive role in making the individual competent at finding the best coping strategy in new situations where prejudice occurs.
In the examples in this article, we have seen that the young people we interviewed had often reflected considerably on why they acted as they did when they experienced exclusion, and whilst the actions were not always planned, there seems to often be a conscious and willed dimension to it. Within what can be felt to be a limited setting, they tried to navigate through their environment to lessen the impact or occurrence of exclusion through their immediate actions or future plans. An implication of the study is that young immigrants and descendants of immigrants who are encouraged to use their background as a positive asset can learn how to find their way through the educational system. Often, young immigrants are advised to aim low in the educational system, since their background is seen as an obstacle, whereas our informants underline that aiming high (that is, if one has the capacity to do so), can be a buffer against future stigmatisation. Another finding is that individuals from ethnic minority backgrounds can benefit from building up strong networks, including those from both ethnic minority and ethnic majority backgrounds.

\section{Acknowledgments}

We would like to thank the cultural sociologists at the Department of Sociology and Human Geography of the University of Oslo, and colleagues at the Centre for the Study of Professions at Oslo and Akershus University College, for their comments on an earlier version of this article. The research leading to the results received funding from the European Community's Seventh Framework Programme (FP7/2007-2013) under grant agreement no 217524 (the EUMARGINS project).

\section{Conflict of Interests}

The authors declare no conflict of interests.

\section{References}

Bandura, A. (1982). Self-efficacy mechanism in human agency, American Psychologist, 37(2), 122-147.

Bandura, A. (1994). Self-efficacy. In V. S. Ramachaudran (Ed.), Encyclopedia of human behavior (Volume 4, pp. 71-81). New York: Academic Press.

Bandura, A. (2000). Exercise of human agency through collective efficacy. Current Directions in Psychological Science, 9(3), 75-78.

Bandura, A. (2001). Social cognitive theory: An agentic perspective. Annual Review of Psychology, 52, 1-26.

Barrett, L. F., \& Swim, J. K. (1998) Appraisals of prejudice and discrimination. In Swim, J. K., \& Stangor, C. (Eds.), Prejudice: The target's perspective (pp. 1136). San Diego, CA: Academic Press.

Borchorst, A. (2011). Scandinavian Gender Equality: Competing Discourses and Paradoxes. In E. Addis, P. 
de Villota, F. Degavre \& J. Eriksen (Eds.), Gender and Well-Being: The Role of Institutions (pp. 63-75). Surrey: Ashgate.

Compas, B. E., Connor-Smith, J. K., Saltzman, H., Harding Thomsen, A., \& Wadsworth, M. E. (2001). Coping with stress during childhood and adolescence: Problems, progress, and potential in theory and research. Psychological Bulletin, 127(1), 87-127.

Fangen, K. (2006). Humiliation as experienced by Somalis in Norway. Journal of Refugee Studies, 19(1), 69-93.

Fangen, K. (2007a). Citizenship among young adult Somalis in Norway. Nordic Journal of Youth Research, 15(4), 413-434.

Fangen, K. (2007b). Breaking up the Different Constituting Parts of Ethnicity-The Case of Young Somalis in Norway. Acta Sociologica, 50(4): 401-414.

Fangen, K. (2010). Social Exclusion and Inclusion of Young Immigrants: Presentation of an Analytical Framework. Nordic Journal of Youth Research, 18(2), 133-156.

Fangen, K. (2012). Analysis of life stories across national borders. In K. Fangen, N. Hammarén, \& T. Johansson (Eds.), Young Migrants: Exclusion and Belonging in Europe (pp. 26-53). Basingstoke: Palgrave MacMillan.

Fangen, K., Fossan, K., \& Mohn, F. A. (Eds.) (2010). Inclusion and Exclusion of Young Adult Immigrants in Europe: Barriers and Bridges. Farnham and Burlington: Ashgate.

Fangen, K., \& Frønes, I. (2013). Structural barriers and individual agency: A mixed-methods approach to school-work transitions among young adult immigrants and descendants. In G. Gudmundsson, D. Beach \& V. Vestel (Eds.), Youth and marginalisation: Young people from immigrant families in Scandinavia. London: Tufnell Press.

Fangen, K, \& Paasche, E. (2013). Young adults of ethnic minority background on the Norwegian labour market: The interactional co-construction of exclusion by employers and customers. Ethnicities, 13(5), 607-624.

Fekjær, S. N. (2007). New differences, old explanations: Can educational differences between ethnic groups in Norway be explained by social background? Ethnicities, 7(3), 367-389.

Finne, S. H. (2010). Indiske etterkommere $i$ eliteut danninger-En kvalitativ studie av utdanningsvalg blant indiske etterkommere i eliteutdanninger (MA thesis). Oslo: Department of Sociology and Human Geography, University of Oslo.

Folkman, S., Lazarus, R. S., Dunkel-Schetter, C., Delongis, A., \& Gruen, R. J. (1986). Dynamics of a stressful encounter: Cognitive appraisal, coping and encounter outcomes. Journal of Personality and Social Psychology, 50(5), 992-1003.

Goffman, E. (1967). Interaction Ritual: Essays in Face-
to-Face-Behaviour. Chicago: Aldine Publishers.

Gullestad, M. (2006). Plausible Prejudice: Everyday Experiences and Social Images of Nation, Culture and Race. Oslo: Scandinavian University Press.

Klein, D. C. (1991). The humiliation dynamic: An overview. Journal of Primary Prevention, 12(2), 93-121.

Kundnani, A. (2002). The death of multiculturalism. Race \& Class, 43(4), 67-72.

Kvittingen, I. (2011). Lik eller unik arbeidstaker? Synlige minoriteters erfaringer med å søke jobb (MA thesis). Oslo: Department of Sociology and Human Geography, University of Oslo.

Lauglo, J. (1999). Working Harder to Make the Grade: Immigrant Youths in Norwegian Schools. Journal of Youth Studies, 2(1), 77-100.

Lindner, E. G. (2000). The Psychology of Humiliation: Somalia, Rwanda/Burundi, and Hitler's Germany (PhD thesis). Oslo, Norway: University of Oslo.

Major, B., \& O'Brien, L. T. (2005). The Social Psychology of Stigma. Annual Review of Psychology, 56(1), 393421.

Miller, C. T., \& Major, B. (2000). Coping with stigma and prejudice. In T. F. Heatherton, R. E. Kleck, M. R. Hebl, \& J. G. Hull (Eds.), The social psychology of stigma (pp. 244-272). New Work, NY: The Guilford Press.

Noh, S., \& Kaspar, V. (2003). Perceived discrimination and depression: Moderating effects of coping, acculturation, and ethnic support. American Journal of Public Health, 93(2), 232-238.

$\varnothing \mathrm{ia}, \mathrm{T} .$, \& Vestel, V. (2007). Møter i det flerkulturelle. NOVA Report 21/07. Oslo: NOVA.

Portes, A., \& Rumbaut, R. G. (2001). Legacies. The Story of the Immigrant Second Generation. Los Angeles: University of California Press.

Puhl, R., \& Brownell, K. D. (2003). Ways of coping with obesity stigma: Review and conceptual analysis. Eating Behaviors, 4(1), 53-78.

Schmitt, M. T., \& Branscombe, N. R. (2002). The meaning and consequences of perceived discrimination in disadvantaged and privileged social groups. European Review of Social Psychology, 12(1), 167-199.

SOPEMI. (2010). International Migration 2010-11. Oslo: Norwegian Ministry of Education and Research.

Støren, L. A. (2010). Unge innvandrere $i$ utdanning og overgang til arbeid. Report no. 45. Oslo: NIFU.

Verkuyten, M. (2004). Everyday ways of thinking about multiculturalism. Ethnicities, 4(1), 53-74.

Wiggen, M. (2012). Rethinking anti-immigration rhetoric after the Oslo and Utøya terror attacks. New Political Science, 34(4), 585-604.

Witoszek, N. (2011). The Origins of the Regime of Goodness. Oslo: Pax.

Wong, C. A., Eccles, J. S., \& Sameroff, A. (2003). The influence of ethnic discrimination and ethnic identification on African American adolescents' school and socioemotional adjustment. Journal of Personality, 71(6), 1197-1232. 


\section{About the Authors}

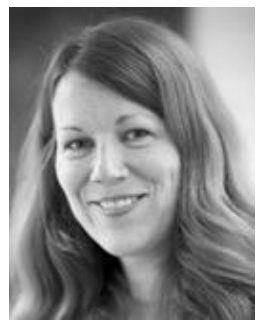

\section{Dr. Katrine Fangen}

Katrine Fangen is Professor in Sociology at the University of Oslo, Department of Sociology and Human Geography. She has published many books and journal articles, mainly within the fields of migration research since 1999 and youth research since 1992. She has also published books and articles on qualitative methods in general and comparative qualitative research and participant observation in particular, as well as on nationalism and right-wing extremism. During recent years, her main focus has been on young migrant's experiences of exclusion and inclusion in Europe as well as on identity navigation, political involvement and citizenship among Norwegian Somalis.

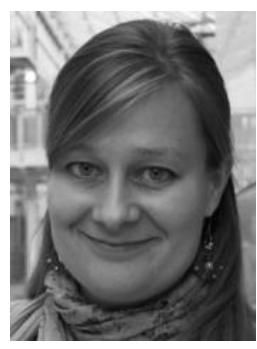

\section{Brit Lynnebakke}

Brit Lynnebakke is a PhD candidate in human geography at The Norwegian Institute for Urban and Regional Research, Oslo. She has a master's degree in Migration and Ethnic Studies from the University of Amsterdam, a major in psychology and a major in anthropology. Lynnebakke has worked on migration issues within research and as a journalist. Within research she has worked on inclusion and exclusion processes, segregation and immigrants' access on the housing market. As a journalist, she has particularly covered migration and peace building, ethnically diverse neighbourhoods and media discourses on immigration and diversity. 